\title{
A case series of medically managed Candida parapsilosis complex prosthetic valve endocarditis
}

Penghao Guo ${ }^{1 \dagger}$, Yuting He ${ }^{1 \dagger}$, Rui Fan², Zhongwen Wu' , Yili Chen ${ }^{1}$, Yuli Huang ${ }^{3}$, Kang Liao ${ }^{1 *}$ and Peisong Chen ${ }^{{ }^{*}}$

\begin{abstract}
Background: In recent years, Candida parapsilosis is recognized as a species complex and is composed of Candida parapsilosis sensu stricto, Candida orthopsilosis and Candida metapsilosis. Candida parapsilosis complex prosthetic valve endocarditis (PVE) is rare and the survival rate is still low despite of optimal therapeutic strategies. In our report, it is novel to report cases as Candida parapsilosis complex PVE at species and identify Candida parapsilosis using MALDITOF MS.

\section{Case presentation}

A series of 4 cases of Candida parapsilosis complex PVE from our institution was reported. Three were infected by Candida parapsilosis sensu stricto and one was infected by Candida metapsilosis. The condition of two cases got better and the other died.

Conclusions: More attention should be paid to Candida parapsilosis complex PVE and early diagnosis and prompt antibiotic therapy may play a role in the treatment for Candida parapsilosis complex PVE. It is recommended to identify Candida parapsilosis complex at species level and MALDI-TOF MS as an easy, fast and efficient identification method is worth promoting in clinical microbiology
\end{abstract}

Keywords: Prosthetic valve endocarditis, Candida parapsilosis complex, Combination antifungal therapy, Matrixassisted laser desorption ionization-time of flight mass spectrometry

\section{Introduction}

Prosthetic valve endocarditis(PVE) is a complication of cardiac valve replacement and is related with a high mortality [1]. What's more, the incidence of PVE is increasing and it accounts for $20-30 \%$ of infective endocarditis episodes [2]. Generally, typical microorganisms causing PVE were mainly bacteria, especially Enterococci and Staphylococcus aureus [3]. Fungal endocarditis(FE) is a rare and fatal form of infectious endocarditis [4]. Candida and

\footnotetext{
*Correspondence: liaokang1971@163.com; chps@mail3.sysu.edu.cn ${ }^{\dagger}$ Penghao Guo and Yuting He contributed equally to this work

1 Department of Clinical Laboratory, The First Affiliated Hospital, Sun YatSen University, 58 Zhongshan road II, Guangzhou, Guangdong, China

Full list of author information is available at the end of the article
}

Aspergillus species are two of the most common etiologic fungi for FE. Among Candida endocarditis, Candida albicans is the main cause of FE and Candida parapsilosis is the most common non-albicans species responsible for FE [5]. In the last years, Candida parapsilosis is recognized as a species complex and is composed of Candida parapsilosis sensu stricto, Candida orthopsilosis and Candida metapsilosis, which are unique but related [6]. The Candida parapsilosis complex is opportunistic fungal pathogen responsible for many human nosocomial infections. Candida parapsilosis complex PVE is rare and the survival rate is still low despite of optimal therapeutic strategies [7]. However, the literature on Candida parapsilosis complex PVE is limited. What's more, the previous studies did not identify Candida parapsilosis complex at

(c) The Author(s) 2021. This article is licensed under a Creative Commons Attribution 4.0 International License, which permits use, sharing, adaptation, distribution and reproduction in any medium or format, as long as you give appropriate credit to the original author(s) and the source, provide a link to the Creative Commons licence, and indicate if changes were made. The images or other third party material in this article are included in the article's Creative Commons licence, unless indicated otherwise in a credit line to the material. If material is not included in the article's Creative Commons licence and your intended use is not permitted by statutory regulation or exceeds the permitted use, you will need to obtain permission directly from the copyright holder. To view a copy of this licence, visit http://creativeco mmons.org/licenses/by/4.0/. The Creative Commons Public Domain Dedication waiver (http://creativecommons.org/publicdomain/ zero/1.0/) applies to the data made available in this article, unless otherwise stated in a credit line to the data. 
species level. More information about Candida parapsilosis complex PVE at species level and the management of it is needed. Here we present a case series of Candida parapsilosis complex PVE in patients with aortic valve replacement (AVR) or mitral valve replacement (MVR) from the First Affiliated Hospital of Sun Yat-Sen University, providing more information about Candida parapsilosis complex PVE at species level and reference on the treatment of it. All patients received detailed counseling and informed written consent was obtained from each participant.

\section{Case description}

\section{Case report 1}

The first patient was a 55-year-old man who had a history of smoking for more than 10 years. The patient underwent mitral valve replacement in 2012. On 24th of December 2017, he was admitted into the First Affiliated Hospital of Sun Yat-Sen University because of aggravated shortness of breath for one month and edema of both lower extremities for 3 days. The initial blood count showed hemoglobin level of $100 \mathrm{~g} / \mathrm{L}$, white blood cell (WBC) count of $5.28 \times 10^{9}$ cells/L (46.6\% neutrophils, $36.2 \%$ lymphocytes), raised erythrocyte sedimentation rate (ESR) $(74 \mathrm{~mm} / \mathrm{h})$ and $\mathrm{C}$-reactive protein $(\mathrm{CRP})(10.60 \mathrm{mg} / \mathrm{L})$. The procalcitonin $(\mathrm{PCT})$, troponin $\mathrm{T}$ and $\mathrm{N}$-terminal prohormone of brain natriuretic peptide (NT-proBNP) all increased (Table S1). Bed-side chest radiograph showed inflammation of both lungs and enlarged heart shadow in the supine position. Transthoracic echocardiography (TTE) showed two vegetations on prosthetic mitral valve and accelerated velocity of the prosthetic mitral valve $(140 \mathrm{~cm} / \mathrm{s})$ The effective orifice area was $1.8 \mathrm{~cm}^{2}$ (Fig. 1), indicating infectious endocarditis after MVR. TTE also found moderate tricuspid regurgitation and mild pulmonary artery hypertension. The left ventricular ejection fraction (LVEF) was approximately normal (56\%) and the diastolic function was reduced. The electrocardiograph (ECG) indicated atrial flutter (2-3: 1 conduction) with rapid ventricular rate. The (1,3)- $\beta$-D glucan was $93.99 \mathrm{pg} / \mathrm{mL}$ and Candida parapsilosis sensu stricto was identified in the blood culture by Matrix-assisted laser desorption ionizationtime of flight mass spectrometry (MALDI TOF-MS) (bioMerieux, France) (Flucytosine minimal inhibitory concentration (MIC) $4 \mathrm{ug} / \mathrm{mL}$, amphotericin B MIC 0.5 $\mathrm{ug} / \mathrm{mL}$, voriconazole MIC $0.06 \mu \mathrm{g} / \mathrm{mL}$, itraconazole MIC $0.125 \mu \mathrm{g} / \mathrm{mL}$, fluconazole MIC $1 \mu \mathrm{g} / \mathrm{mL}$ ). The cutoff values for antifungal susceptibility testing were on the basis of CLSI M59 and CLSI M60 [8, 9]. Repeat blood cultures continued to grow Candida parapsilosis sensu stricto. The patient was initiated on vancomycin $1 \mathrm{~g}$ iv three times a day and voriconazole $200 \mathrm{mg}$ iv twice a day after admission. Then, combination antifungal therapy with vancomycin $1 \mathrm{~g}$ iv three times a day and caspofungin iv $50 \mathrm{mg}$ once a day was initiated on Dec 29. Because of high vancomycin blood concentration, the therapy changed to vancomycin $1 \mathrm{~g}$ iv twice a day and caspofungin $50 \mathrm{mg}$ iv once a day on Dec 30 and lasted until discharging. Besides, ceftriaxone sodium was administrated from Dec 30 of 2017 to Jan 3 of 2018 to fight lung infections. After a series of anti-infective treatment, the patient's condition improved. However, the blood cultures continued to grow Candida parapsilosis sensu stricto and the patient refused the surgical treatment despite of the indications of operation. The patient went back to local hospital and was recommended to continue the combination antifungal therapy according to the drug sensitivity.
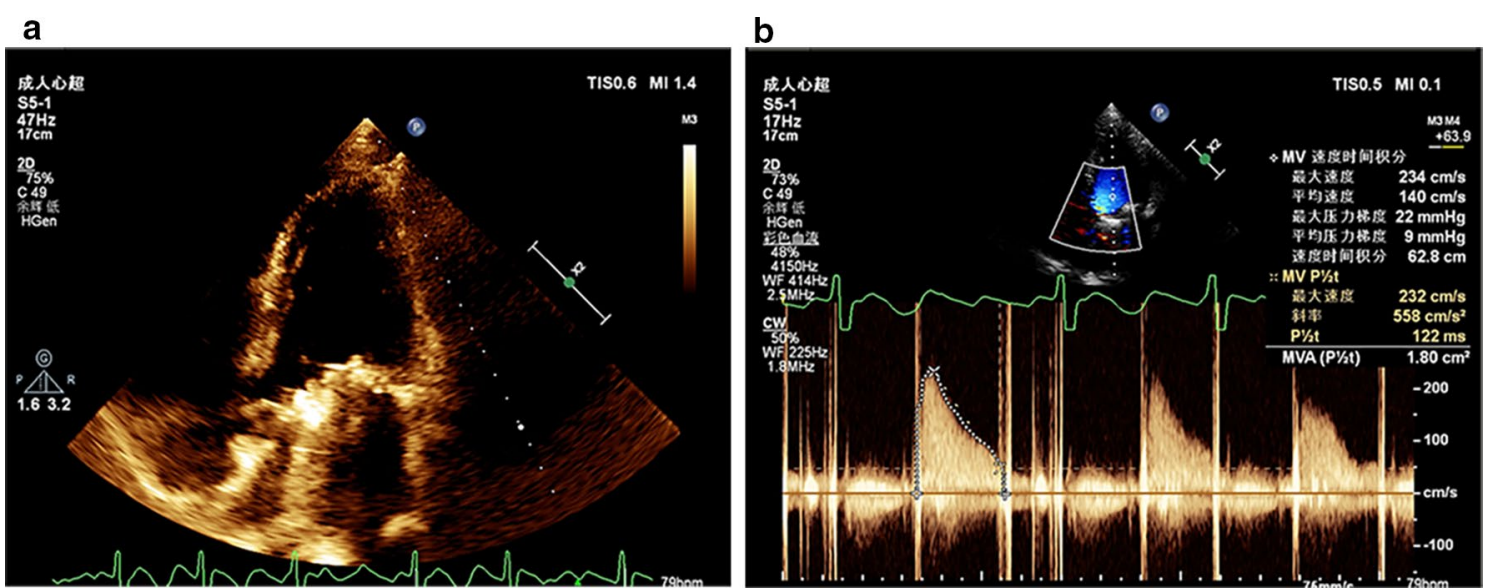

Fig. 1 The Candida parapsilosis complex prosthetic valve endocarditis of case 1. a Echocardiography showed a vegetation on the artificial mitral valve. b The Color Doppler showed increased flow rate at the prosthetic mitral valve orifice and tricuspid regurgitation (moderate) 


\section{Case report 2}

The second patient was a 71-year-old man with a history of hypertension for 3 years and smoking for 30 years. He was admitted into the First Affiliated Hospital of Sun Yat-Sen University on April 26 of 2019 for repeated chest tightness and palpitations for more than 10 years, aggravating by 1 year. TTE showed that posterior mitral valve tendon cord was ruptured, which resulted in posterior mitral valve prolapse and severe mitral valve regurgitation. At the same time, TEE found mild aortic valve stenosis and mild-moderate regurgitation, anterior tricuspid valve prolapse and medium regurgitation, severe pulmonary artery hypertension. The aorta root, the left atrium and left ventricle were significantly enlarged. The right atrium was slightly larger and the left ventricular ejection fraction (LVEF) was about $70 \%$. On May 5 , the patient underwent aortic valve and mitral valve bioprosthesis replacement, tricuspid valvuloplasty, aortic annuloplasty and temporary cardiac pacemaker implantation. The patient was given cefperazone-sulbactam $3 \mathrm{~g}$ iv three times a day from May 5 to May 17, cilastatin sodium/imipenem iv $1 \mathrm{~g}$ once a day from May 20 to May 28 and cefperazone-sulbactam $3 \mathrm{~g}$ iv three times a day from May 28 to May 31. On May 24, the blood culture grew yeast-like fungus and the yeast-like fungus was identified Candida parapsilosis sensu stricto by MALDI TOF-MS (bioMerieux, France) (Flucytosine MIC $4 \mathrm{ug} / \mathrm{mL}$, amphotericin B MIC $0.5 \mathrm{ug} / \mathrm{mL}$, voriconazole MIC $0.06 \mathrm{ug} / \mathrm{mL}$, itraconazole MIC $0.125 \mathrm{ug} / \mathrm{mL}$, fluconazole MIC $1 \mu \mathrm{g} / \mathrm{mL}$ ). Then the patient was administrated caspofungin $(50 \mathrm{mg}$ iv once day) to fight fungal infection. On June 13, the blood culture still grew Candida parapsilosis sensu stricto and the patient continued to use caspofungin $(50 \mathrm{mg}$ iv once day). On June 24 , the patient had a fever of $39.2^{\circ} \mathrm{C}$ and the blood culture still Candida parapsilosis sensu stricto. Then the patient was given voriconazole $(200 \mathrm{mg}$ oral twice a day) instead of caspofungin. The blood culture became negative after 1 month using voriconazole. The patient continued to use voriconazole (200 mg oral once a day) for 2 weeks after discharging.

Six months later, the patient was readmitted into the First Affiliated Hospital of Sun Yat-Sen University on November 4 due to fever for 20 days and shortness of breath for 3 days after activity. The initial blood count showed WBC count of $3.76 \times 10^{9}$ cells/L (78.8\% neutrophils, $10.3 \%$ lymphocytes). The $(1,3)-\beta$-D glucan was $144.85 \mathrm{pg} / \mathrm{mL}$ and the blood culture grew Candida parapsilosis sensu stricto which was identified by MALDI TOF-MS (bioMerieux, France) (Flucytosine MIC $4 \mu \mathrm{g} /$ $\mathrm{mL}$, amphotericin B MIC $0.5 \mathrm{ug} / \mathrm{mL}$, voriconazole MIC $0.06 \mu \mathrm{g} / \mathrm{mL}$, itraconazole MIC $0.125 \mathrm{ug} / \mathrm{mL}$, fluconazole MIC $1 \mathrm{ug} / \mathrm{mL}$ ). (Table 1 and Additional file 1: Table S1). TEE showed a dehiscence about $10.3 \times 6.1 \mathrm{~mm}$ and severe perivalvular leakage from the medial part of the prosthetic mitral valve. TEE also found a small strip fluttering a lot from left atrium side of the medial prosthetic ring, suggesting infective endocarditis (Fig. 2). The patient was administrated voriconazole $200 \mathrm{mg}$ iv twice a day from November 4 to 21, caspofungin $50 \mathrm{mg}$ iv twice a day from November 21 to December 4 and amphotericin B $1 \mathrm{mg}$ iv once a day from November 26 to December 4 . Besides, the patient was administrated piperacillin-tazobactam $4.5 \mathrm{~g}$ iv three times a day from Nov 4 to Nov 6, vancomycin $0.5 \mathrm{~g}$ iv once a day from Nov 17 to Nov 21 and cilastatin sodium/imipenem iv $1 \mathrm{~g}$ once a day from Nov 21 to Dec 4. The patient's body temperature was relieved, fluctuating around $37.5{ }^{\circ} \mathrm{C}$. Then the patient was discharged and recommended antifungal treatment in local hospital with cilastatin sodium/imipenem for injection $1000 \mathrm{mg}$ three times a day, caspofungin $50 \mathrm{mg}$ once a day and amphotericin B $30 \mathrm{mg}$ once a day.

\section{Case report 3}

The third patient was a 70-year-old man who underwent aortic valve replacement in 2011 and was admitted in the First Affiliated Hospital of Sun Yat-Sen University on November 22 of 2015 due to repeated fever for more than 50 days and acute bloating for 12 days. The initial blood count showed WBC count of $2.95 \times 10^{9}$ cells/L $(64.8 \%$ neutrophils, $22.7 \%$ lymphocytes). The PCT, troponin T, NT-proBNP and the $(1,3)-\beta-\mathrm{D}$ glucan all increased. (Table S1). The TTE showed a hypoechoic vegetation was formed on prosthetic aortic valve and the size of the vegetation was about $17.8 \times 8.0 \mathrm{~mm}$. Besides, enlarged left atrium and left ventricle, mild-moderate mitral valve regurgitation, moderate tricuspid regurgitation, moderate pulmonary artery hypertension was found. The LVEF was about $74 \%$ and diastolic function of left ventricular was reduced (grade I) (Fig. 3). Abdominal examination showed gas accumulation in the intestine, indicating intestinal obstruction. The patient presented septic shock, poor heart function and arrhythmia, incomplete intestinal obstruction and water and electrolyte balance disorders. The blood culture grew Candida parapsilosis sensu stricto (Flucytosine MIC $4 \mu \mathrm{g} / \mathrm{mL}$, amphotericin B MIC $0.5 \mu \mathrm{g} / \mathrm{mL}$, voriconazole MIC $0.06 \mu \mathrm{g} / \mathrm{mL}$, itraconazole MIC $0.125 \mu \mathrm{g} / \mathrm{mL}$, fluconazole MIC $1 \mu \mathrm{g} / \mathrm{mL}$ ). The patient was given anti-infection and anti-shock treatment. The patient was administrated fluconazole $100 \mathrm{mg}$ iv once a day from November 23 to November 27 and voriconazole $200 \mathrm{mg}$ iv twice a day. Besides, the patient was also given cefperazone-sulbactam $3 \mathrm{~g}$ iv three times a day from November 22 to December 4. Fourteen days after a series of treatments, the patient presented cardiac rhythm of 130 beats $/ \mathrm{min}$, atrial fibrillation rhythm, blood pressure of $100 / 60 \mathrm{mmHg}$, maximum temperature $40{ }^{\circ} \mathrm{C}$, 
Table 1 Clinical characteristics of the patients

\begin{tabular}{|c|c|c|c|c|}
\hline & Case 1 & Case 2 & Case 3 & Case 4 \\
\hline Age(years) & 55 & 71 & 70 & 64 \\
\hline Gender & Male & Male & Male & Male \\
\hline Type of surgery & Mitral valve replacement & $\begin{array}{l}\text { Aortic and mitral valve } \\
\text { replacement }\end{array}$ & Aortic valve replacement & $\begin{array}{l}\text { Aortic and mitral valve } \\
\text { replacement }\end{array}$ \\
\hline Type of valve replacement & / & $\begin{array}{l}\text { Medtronic Hanko II 27\# } \\
\text { (mitral valve); Medtronic } \\
\text { Hanko II 21\# (aortic valve) }\end{array}$ & / & $\begin{array}{l}\text { Edward 25\# (mitral valve); } \\
\text { Edward 21\# (aortic } \\
\text { valve) }\end{array}$ \\
\hline $\begin{array}{l}\text { Possible predisposing factor } \\
\text { for infective endocarditis }\end{array}$ & Smoking & $\begin{array}{l}\text { Fungemia Hypertension } \\
\text { Smoking }\end{array}$ & / & Hepatitis B \\
\hline Symptoms on admission & $\begin{array}{l}\text { Aggravated shortness of } \\
\text { breath for one month } \\
\text { and edema of both lower } \\
\text { extremities for } 3 \text { days }\end{array}$ & $\begin{array}{l}\text { Fever for } 20 \text { days and short- } \\
\text { ness of breath for } 3 \text { days } \\
\text { after activity }\end{array}$ & $\begin{array}{l}\text { Repeated fever for more than } \\
50 \text { days and acute bloating } \\
\text { for } 12 \text { days }\end{array}$ & $\begin{array}{l}\text { Repeated fever for nearly } \\
2 \text { months }\end{array}$ \\
\hline Infection site & Mitral valve & Mitral valve & Aortic valve & Mitral valve \\
\hline Time post implantation & Five years & Six months & Four years & Three years \\
\hline $\begin{array}{l}\text { Pathogen (isolated from } \\
\text { blood) }\end{array}$ & $\begin{array}{l}\text { Candida parapsilosis sensu } \\
\text { stricto }\end{array}$ & $\begin{array}{l}\text { Candida parapsilosis sensu } \\
\text { stricto }\end{array}$ & $\begin{array}{l}\text { Candida parapsilosis sensu } \\
\text { stricto }\end{array}$ & Candida metapsilosis \\
\hline \multicolumn{5}{|l|}{ MIC (ug/mL) } \\
\hline 5-Flucytosine & 4 & 4 & 4 & 4 \\
\hline Amphotericin B & 0.5 & 0.5 & 0.5 & 0.5 \\
\hline Voriconazole & 0.06 & 0.06 & 0.06 & 0.06 \\
\hline Itraconazole & 0.125 & 0.125 & 0.125 & 0.125 \\
\hline Fluconazole & 1 & 1 & 1 & 2 \\
\hline Choice ofantifungal drugs & Voriconazole, caspofungin & $\begin{array}{l}\text { Voriconazole, caspofungin, } \\
\text { amphotericin B }\end{array}$ & Voriconazole, fluconazole & Fluconazole, caspofungin \\
\hline Outcome & Successful medical therapy & Successful medical therapy & Death & Death \\
\hline
\end{tabular}

MIC minimal inhibitory concentration

30 breaths/min, SPO2 84-90\% and SPO2\% 90-94 under mask oxygen inhalation. The patient finally died in spite of a series of emergency measures.

\section{Case report 4}

The fourth patient was a 64 year-old man with a history of hepatitis B and underwent aortic bioprosthesis valve replacement and mitral bioprosthesis valve replacement in 2016. Three years later, the patient was readmitted into the First Affiliated Hospital of Sun Yat-Sen University on November 7 of 2019 because of repeated fever for nearly 2 months without incentive. The initial blood count showed WBC count of $3.91 \times 10^{9}$ cells/L (73.7\% neutrophils, $18.8 \%$ lymphocytes). The PCT, troponin T and NTproBNP were $0.61 \mathrm{ng} / \mathrm{mL}, 0.059 \mathrm{ng} / \mathrm{mL}$ and $10,864 \mathrm{pg} /$ $\mathrm{mL}$ respectively, which were all increased. Bedside echocardiography showed the prosthetic mitral valve functioned normally, but there was a vegetation which was nearly $19 \times 10 \mathrm{~mm}$. The blood culture grew candida metapsilosis which was identified by MALDI TOF-MS (bioMerieux, France) (Flucytosine MIC $4 \mathrm{ug} / \mathrm{mL}$, amphotericin B MIC $0.5 \mathrm{ug} / \mathrm{mL}$, voriconazole MIC $0.06 \mathrm{ug} / \mathrm{mL}$, itraconazole MIC $0.125 \mathrm{ug} / \mathrm{mL}$, fluconazole MIC $2 \mathrm{ug} /$
$\mathrm{mL}$ ) (Table 1 and Additional file 1: Table S1). Then the patient was administrated fluconazole $100 \mathrm{mg}$ iv once a day from November 7 to 9 and caspofungin $50 \mathrm{mg}$ iv once a day from November 9 to 10, as well as cefperazone-sulbactam $3 \mathrm{~g}$ iv three times a day for four days. On the fourth day of admission, the patient had a ventricular fibrillation suddenly. After a series of rescue measures, the patient's condition didn't improve and died.

\section{Discussion}

With the increasing infection rate of Candida, Candida endocarditis especially Candida parapsilosis complex endocarditis gains more and more attention because of its high mortality and morbidity $[10,11]$. In recent years, with the widespread application of life support systems, Candida parapsilosis complex has become the second most common pathogen of candidiasis. Candida parapsilosis complex is the normal flora colonizing on gastrointestinal tract, skin and oropharynx. The general incentives for Candida parapsilosis complex contain the prosthetic valves (57.4\%), IV drug use (IVDU; 20\%), IV parenteral nutrition (6.9\%), abdominal surgery $(6.9 \%)$, immunosuppression $(6.4 \%)$, using 

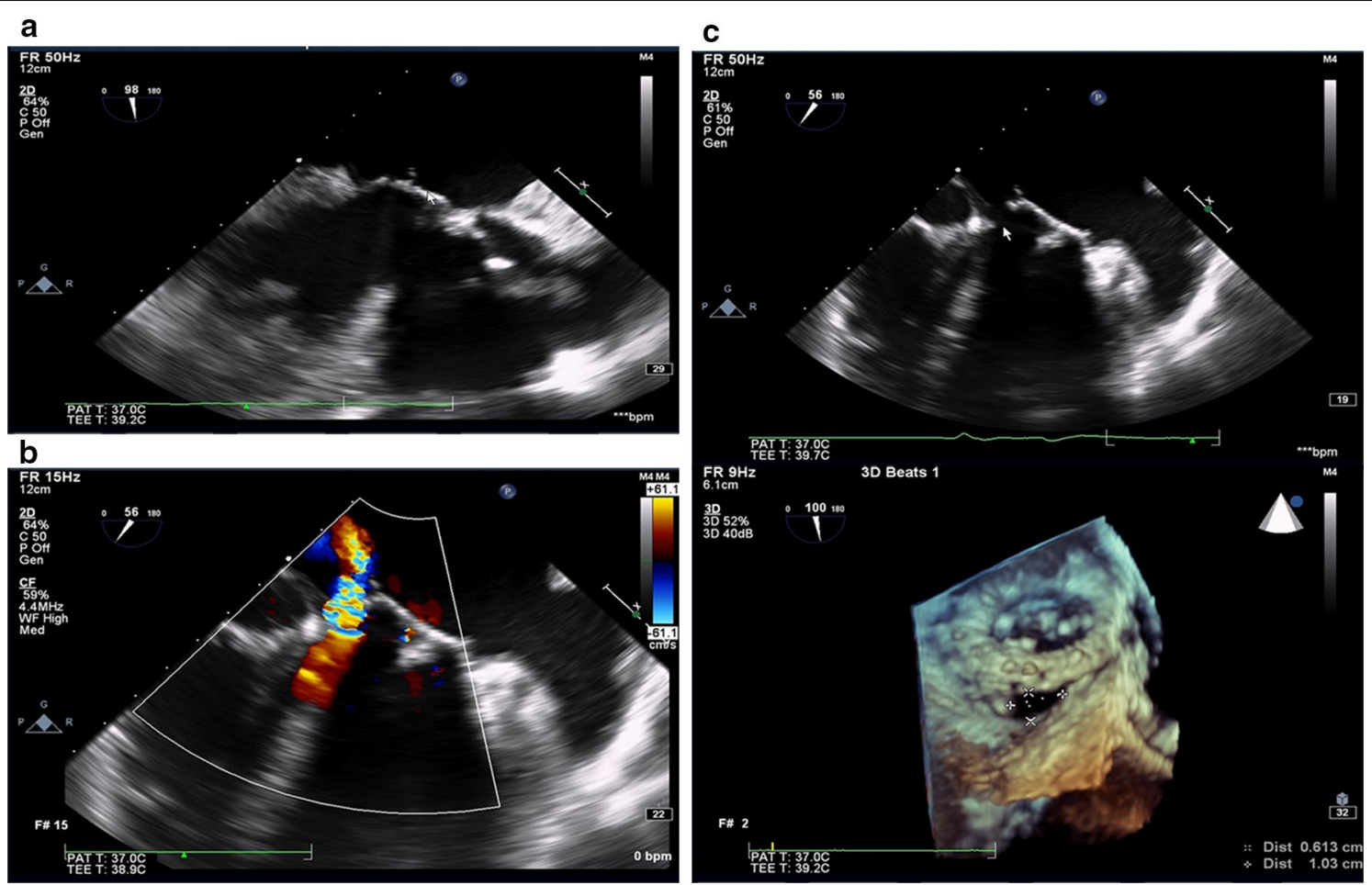

Fig. 2 The Candida parapsilosis complex prosthetic valve endocarditis of case 2. a Echocardiography showed a short abnormal strip about $5 \mathrm{~mm} \times 3 \mathrm{~mm}$ on the prosthetic mitral valve of the left atrium side; $\mathbf{b}$ The Color Doppler showed perivalvular leakage (moderate-severe); $\mathbf{c}$ Transesophageal 3D image showing a bioprosthetic mitral valve. A perivalvular crack about $10.3 \times 6.1 \mathrm{~mm}$ could be seen around the medial side of the prosthetic mitral valve

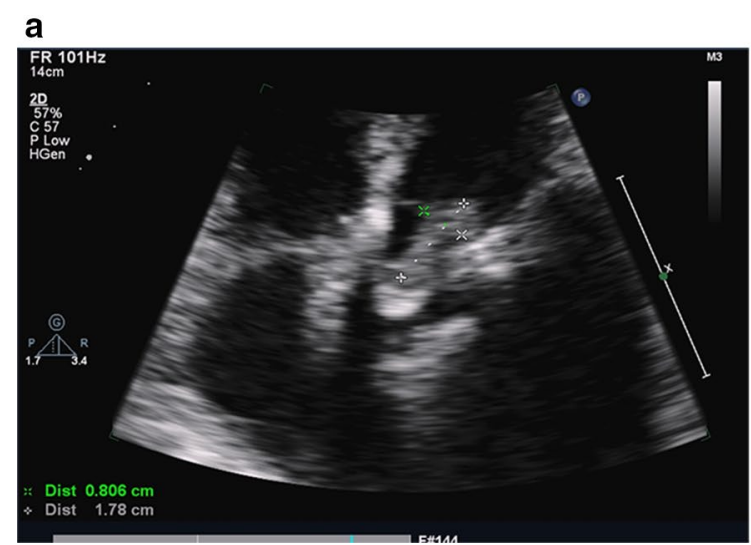

\section{b}

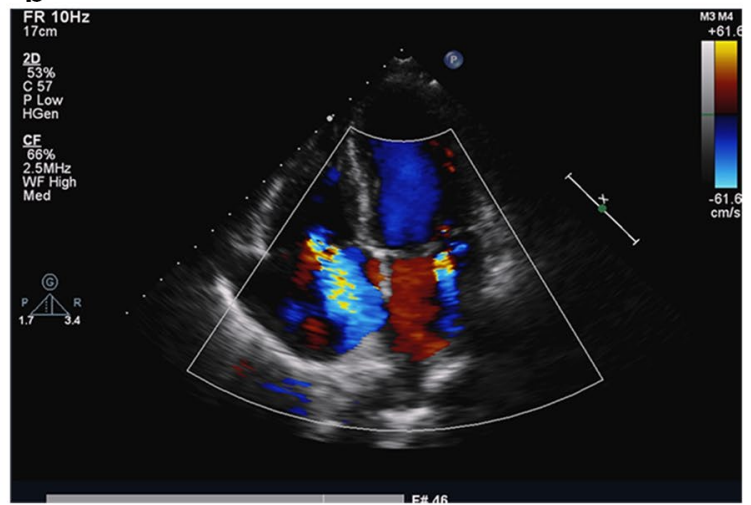

Fig. 3 The Candida parapsilosis complex prosthetic valve endocarditis of case 3. a TTE showed a hypoechoic vegetation on the artificial aortic valve and the vegetation was about $17.8 \times 8.0 \mathrm{~mm}$; b Mild to moderate mitral regurgitation and moderate tricuspid regurgitation were observed on Doppler color view

broad-spectrum antibiotics (5.6\%) and previous valvular disease (4.8\%) [12]. Candida parapsilosis strains are heterogeneous. Recently, Candida parapsilosis is recognized as a species complex. Tavanti et al. [13]suggested to divide Candida parapsilosis group into three species named Candida parapsilosis sensu stricto, Candida orthopsilosis and Candida metapsilosis. The biological phenotypic characteristics of the three species of fungi are basically the same but they belong to different genotypes. Conventional fungal identification 
methods cannot distinguish between them. They can only be distinguished by Matrix-assisted laser desorption ionization-time of flight mass spectrometry (MALDI TOF-MS) or molecular biology method. In the previous reports (Table 2) [14-24], the authors all did not distinguish the three species of Candida parapsilosis and just described the cases as Candida parapsilosis PVE. However, in our report, we distinguish the three species of Candida parapsilosis. In our study, there were three cases of Candida parapsilosis sensu stricto and one case of Candida metapsilosis. Species of Candida parapsilosis complex are important pathogens of nosocomial infections and the molecular identification of Candida parapsilosis complex at the species level is essential for optimal treatment and study of nosocomial cross-transmission [25]. Thus, it is recommended to identify Candida parapsilosis complex at species level.

Thanks to the development of matrix-assisted laser desorption ionization time-of-flight mass spectrometry (MALDI-TOF MS), it becomes easy, fast and convenient to identify Candida parapsilosis at the species level. In our report, we identified the Candida parapsilosis at the species level by MALDI-TOF MS quickly and accurately. Most of previous reports (Table 2) did not give out definite method to identify the Candida parapsilosis and they also did not identify it at the species level. Usually, conventional phenotypic identification techniques and gene sequencing are the main methods used to identify the microorganisms in clinical microbiology laboratories.

Table 2 Cases and clinical management of Candida Parapsilosis complex prosthetic valve endocarditis

\begin{tabular}{|c|c|c|c|c|c|c|c|c|}
\hline \multirow[t]{2}{*}{ Age/Sex } & \multirow[t]{2}{*}{ Interval } & \multicolumn{2}{|l|}{ Diagnosis } & \multicolumn{2}{|l|}{ Initial therapy } & \multirow[t]{2}{*}{ Maintenance therapy } & \multirow[t]{2}{*}{ Survive } & \multirow[t]{2}{*}{ Author and references } \\
\hline & & Blood culture & $\begin{array}{l}\text { Culture } \\
\text { from focus }\end{array}$ & Antifungal drugs & Surgery & & & \\
\hline $55 / F$ & 22 days & + & & / & / & / & No & Otaki et al [14] \\
\hline $67 / M$ & / & + & / & $\begin{array}{l}\text { amphotericin B; flucy- } \\
\text { tosine }\end{array}$ & Yes & $\begin{array}{l}\text { Oral fluconazole } \\
400 \text { mg daily }\end{array}$ & Yes & Darwazah et al [15] \\
\hline $59 / \mathrm{M}$ & 11 months & + & + & $\begin{array}{l}\text { amphotericin B, flucy- } \\
\text { tosine }\end{array}$ & Yes & $\begin{array}{l}\text { Fluconazole, } 200 \mathrm{mg} \\
\text { daily, for six months }\end{array}$ & Yes & Jones et al [16] \\
\hline $82 / \mathrm{M}$ & 5 months & / & + & $7.6 \mathrm{~g} \mathrm{AmBisome}$ & Yes & / & No & Jones et al [16] \\
\hline $54 / \mathrm{M}$ & l & / & + & $\begin{array}{l}\text { amphotericin B flucona- } \\
\text { zole } \\
\text { 5-flucytosine }\end{array}$ & Yes & $\begin{array}{l}\text { Amphotericin B and } \\
\text { flucytosine }\end{array}$ & Yes & Kumar et al [17] \\
\hline $44 / F$ & 6 weeks & + & / & / & / & / & / & Mvondo, et al [18] \\
\hline $36 / M$ & 10 months & / & + & $\begin{array}{l}\text { caspofungin, ampho- } \\
\text { tericin B }\end{array}$ & Yes & $\begin{array}{l}\text { Oral antifungal suppres- } \\
\text { sive therapy }\end{array}$ & Yes & Pepe et al [19] \\
\hline $35 / F$ & 3 years & / & + & Amphotericin B, & Yes & / & No & Shokohi et al [20] \\
\hline $47 / M$ & 2 years & + & / & $\begin{array}{l}\text { amphotericin B, 5- flu- } \\
\text { cytosine, micafungin }\end{array}$ & Yes & $\begin{array}{l}\text { Suppressive therapy } \\
\text { with fluconazole }\end{array}$ & Yes & Silva-Pinto et al [21] \\
\hline $31 / F$ & / & + & + & Amphotericin B & Yes & $\begin{array}{l}\text { Long-term prescription } \\
\text { of fluconazole }\end{array}$ & Yes & Kabach et al [22] \\
\hline $69 / M$ & / & + & / & $\begin{array}{l}\text { amphotericin } \mathrm{B}_{\text {, }} \\
\text { micafungin, flucona- } \\
\text { zole }\end{array}$ & No & $\begin{array}{l}\text { Chronic suppression } \\
\text { with fluconazole }\end{array}$ & Yes & Ahuja et al [23] \\
\hline $45 / M$ & $>10$ years & + & / & $\begin{array}{l}\text { amphotericin } \mathrm{B}_{1} \\
\text { micafungin, flucona- } \\
\text { zole }\end{array}$ & No & $\begin{array}{l}\text { Long-term prescription } \\
\text { of flucytosine and } \\
\text { fluconazole }\end{array}$ & Yes & Ahuja et al [23] \\
\hline $24 / F$ & 5 years & + & / & / & Yes & $\begin{array}{l}\text { Oral caspofungin and } \\
\text { daily aspirin }\end{array}$ & Yes & Tan et al [24] \\
\hline $55 / M$ & 5 years & + & / & $\begin{array}{l}\text { Voriconazole, caspo- } \\
\text { fungin }\end{array}$ & No & / & Yes & Our report \\
\hline $71 / \mathrm{M}$ & 6 months & + & / & $\begin{array}{l}\text { Voriconazole, caspo- } \\
\text { fungin, amphotericin } \\
\text { B }\end{array}$ & No & $\begin{array}{l}\text { Caspofungin } 50 \text { mg } \\
\text { once a week and } \\
\text { amphotericin B } 30 \text { mg } \\
\text { once a week }\end{array}$ & Yes & Our report \\
\hline $70 / \mathrm{M}$ & 4 years & + & / & $\begin{array}{l}\text { Voriconazole, flucona- } \\
\text { zole }\end{array}$ & No & / & No & Our report \\
\hline $64 / M$ & 3 years & + & / & $\begin{array}{l}\text { Fluconazole, caspo- } \\
\text { fungin }\end{array}$ & No & / & No & Our report \\
\hline
\end{tabular}




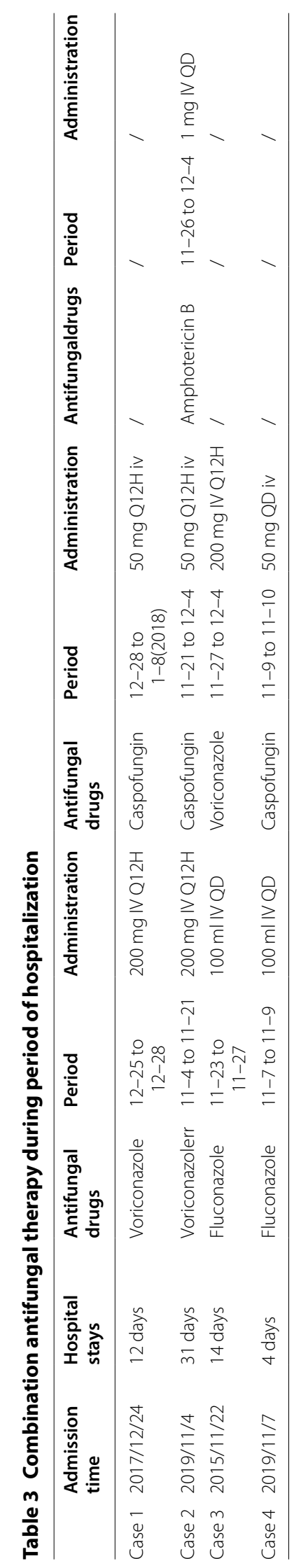


With the development of MALDI-TOF MS, this technology has been adopted in clinical microbiology and it tends to be a gold standard for microbial identification [26]. On the one hand, MALDI-TOF MS can give accurate identification of most Gram-positive, Gram-negative bacterial strains and yeast isolates at the species level [27]. On the other hand, it is easy, fast, cheap, and efficient. This technology identifies each microorganism according to the analysis of mass spectra of the microorganism' protein. By comparing the mass spectrum of the identifying microorganism with that in database of reference spectra, the microorganism could be identified at the family, genus, or species level [28]. Moreover, we usually just need pick a colony from a culture plate to spot on the target plate and add the matrix to the spot. After drying, the target plate should be taken to the mass spectrometer's ionization chamber and the analysis can be finished within a few minutes. MALDI-TOF MS as an easy, fast and efficient identification method has advantages over conventional methods and owns the potential to influence clinical diagnostics and microbial research in the future, making it worth promoting.

No definitive treatment is recommended for Candida parapsilosis complex PVE and consensus on the best medical treatment and on its duration is limited. In recent years, the therapy tends to become combination antifungal therapy and the use of echinocandin is increasing $[29,30]$. The echinocandins are newly developed class of synthetic antifungals which could inhibit the synthesis of 1,3- $\beta$-D-glucan synthase noncompetitively. Moreover, echinocandins can be used against the fluconazoleresistant Candida parapsilosis complex. Although the Candida parapsilosis complex may have echinocandin resistance but it is uncommon. In our case series, the combination antifungal therapy for them were mainly the combination of azoles and echinocandins and the combination antifungal therapies for them during period of hospitalization were shown in Table 3. Moreover, the therapy obtained good outcomes in the patients who came to the hospital earlier, indicating early diagnosis and prompt antibiotic therapy were essential during the treatment of Candida parapsilosis complex PVE. Usually, the clinical features of Candida parapsilosis complex PVE are non-specific. In our case series, the patients only presented fever or shortness of breath. Case 1 and case 2 came to see a doctor within one month when the symptoms appeared while case 3 and case 4 saw the doctor 2 months later. The outcomes of case 1 and case 2 were successful medical therapy while the conditions of case 3 and case 4 deteriorated, making it important to diagnose Candida parapsilosis complex PVE as early as possible. Besides, in the previous reports, the case in Tan's report was admitted one month after initial symptoms and the case in Silva-Pinto's report was admitted ten days after initial symptoms $[21,24]$. These cases all had a successful medical therapy. However, the case of Shokohi who was admitted 35 days after initial symptoms died after a series of emergency measures [20]. The other cases didn't give out definite time point. In fact, the cases concerning the Candida parapsilosis complex prosthetic valve endocarditis are relatively few and some cases didn't present them in detail. Although the reasons for the outcomes of the patients varied, it is undeniable that early diagnosis influences the outcomes of the patients from the limited cases. Fungus is opportunistic pathogen and fungal infections are an important cause of morbidity and mortality in the immunocompromised population. On the one hand, the therapy that could reduce immunity such as the use of glucocorticoid may increase the risk of Candida parapsilosis complex PVE in patients who underwent valve replacement. On the other hand, the physical conditions of the patients could influence the risk of Candida parapsilosis complex PVE. When treating immunocompromised patients who had valve replacement, we should watch out for Candida parapsilosis complex PVE.

Through up-to-date review of all previous cases, 12 cases of Candida parapsilosis complex prosthetic valve endocarditis had been reported (Table 2). Besides, two articles described outbreaks of Candida parapsilosis prosthetic valve endocarditis following cardiac surgery, including 8 dead cases and one alive case without detailed information [31, 32]. Among the listed cases including our cases, 9 cases both chose antifungal drugs and valve replacement to treat Candida parapsilosis complex prosthetic valve endocarditis while the treatment for it tended to combination antifungal therapy rather than surgery in the Ahuja's cases. The literature about Candida parapsilosis complex PVE is limited. Moreover, most of previous reports did not give out detail description of their cases. Thus, more literature with detailed description about Candida parapsilosis complex PVE and the management of it is needed, providing reference to clinicians when treating Candida parapsilosis complex PVE.

In summary, our study raises significant learning points about the medical management and combination antifungal therapy for Candida parapsilosis complex PVE, providing reference for the treatment of Candida parapsilosis complex PVE to other clinicians. These cases also emphasize the challenges when treating Candida parapsilosis complex PVE. Besides, it is recommended to identify Candida parapsilosis complex at species level. MALDI-TOF MS as an easy, fast and efficient identification method is worth promoting in clinical microbiology diagnostics and microbial research in the future. Early diagnosis and prompt antibiotic therapy may play a role in the treatment for Candida parapsilosis complex PVE 
and more attention should be paid to the immunocompromised patients who underwent valve replacement.

\section{Supplementary Information}

The online version contains supplementary material available at https://doi. org/10.1186/s12941-020-00409-4.

Additional file 1: Table S1. Routine analysis of blood, infectious and cardiac function indexes, and indicators of coagulation function on the day of admission.

\section{Acknowledgements}

Not applicable

\section{Authors' contributions}

Penghao Guo designed the work; Kang Liao have drafted the work and Peisong Chen substantively revised it; Yuting He was a major contributor in writing the manuscript; Rui Fan analyzed and interpreted the patient data; Zhongwen Wu was responsible for the acquisition of the data and Yili Chen was also responsible for the acquisition of the data. Yuli Huang was responsible for the imaging processing. All authors read and approved the final manuscript.

\section{Funding}

None.

\section{Availability of data and materials}

Not applicable.

\section{Ethics approval and consent to participate}

The approval for our study was obtained from the institutional review board of the First Affiliated Hospital, Sun Yat-sen University. All patients and their next to kins received detailed counseling and informed written consent to publish for this study was obtained from each participant or their next to kins.

\section{Consent for publication}

Not applicable.

\section{Competing interests}

The authors declare that they have no competing interests.

\section{Author details}

${ }^{1}$ Department of Clinical Laboratory, The First Affiliated Hospital, Sun Yat-Sen University, 58 Zhongshan road II, Guangzhou, Guangdong, China. ${ }^{2}$ Department of Ultrasound, Institute of Diagnostic and Interventional Ultrasound, The First Affiliated Hospital, Sun Yat-Sen University, Guangzhou, China. ${ }^{3}$ Clinical Medicine Research Center, Shunde Hospital, Southern Medical University, Foshan, People's Republic of China.

Received: 22 October 2020 Accepted: 8 December 2020

Published online: 05 January 2021

\section{References}

1. Mahesh B, Angelini G, Caputo M, Jin XY, Bryan A. Prosthetic valve endocarditis. Ann Thorac Surg. 2005;80(3):1151-8.

2. Nataloni M, Pergolini M, Rescigno G, Mocchegiani R. Prosthetic valve endocarditis. J Cardiovasc Med (Hagerstown). 2010;11(12):869-83.

3. Amat-Santos IJ, Ribeiro HB, Urena M, et al. Prosthetic valve endocarditis after transcatheter valve replacement: a systematic review. JACC Cardiovasc Interv. 2015;8(2):334-46.

4. Yuan SM. Fungal endocarditis. Braz J Cardiovasc Surg. 2016;31 (3):252-5.

5. Whaley SG, Berkow EL, Rybak JM, Nishimoto AT, Barker KS, Rogers PD. Azole antifungal resistance in Candida albicans and emerging non-albicans Candida species. Front Microbiol. 2016;7:2173.
6. Cordeiro RA, Sales JA, Castelo-Branco D, et al. Candida parapsilosis complex in veterinary practice: a historical overview, biology, virulence attributes and antifungal susceptibility traits. Vet Microbiol. 2017;212:22-30.

7. Aldosari MA, Alghamdi MH, Alhamdan AA, Alamri MM, Ahmed AM, Aziz MS. Native valve fungal endocarditis caused by Aspergillus fumigatus: management dilemma. Oxf Med Case Reports. 2020;2020(3):omz147.

8. Clinical and Laboratory Standards Institute. Epidemiological Cutoff Values for Antifungal Susceptibility Testing. 3rd ed. New York: Clinical and Laboratory Standards Institute, Wayne, PA; 2020.

9. Clinical and Laboratory Standards Institute. Performance Standards for Antifungal Susceptibility Testing of Yeasts. 2nd ed. New York: Clinical and Laboratory Standards Institute, Wayne, PA; 2020.

10. Pappas PG, Kauffman CA, Andes DR, et al. Clinical practice guideline for the management of candidiasis: 2016 update by the Infectious Diseases Society of America. Clin Infect Dis. 2016;62(4):e1-50.

11. Mamtani S, Aljanabi NM, Gupta Rauniyar RP, Acharya A, Malik BH. Candida endocarditis: a review of the pathogenesis, morphology, risk factors, and management of an emerging and serious condition. Cureus. 2020;12(1):e6695.

12. Jain AG, Guan J, D'Souza J. Candida parapsilosis: an unusual cause of infective endocarditis. Cureus. 2018;10(11):e3553.

13. Tavanti A, Davidson AD, Gow NA, Maiden MC, Odds FC. Candida orthopsilosis and Candida metapsilosis spp. Nov. to replace Candida parapsilosis groups II and III. J Clin Microbiol. 2005;43(1):284-92.

14. Otaki M, Kawashima M, Yamaguchi A, Kitamura N. A case report of Candida prosthetic endocarditis: an autopsy review. Kyobu eka Jpn J Thoracic Surg. 1992:45(4):335-8.

15. Darwazah A, Berg G, Faris B. Candida parapsilosis: an unusual organism causing prosthetic heart valve infective endocarditis. J Infect. 1999;38(2):130-1.

16. Jones JM, Sarsam MA, Clarke MA, Hedderwick SA. Candida parapsilosis: two cases of endocarditis in association with the Toronto stentless porcine valve. J Infect. 2002;44(3):196-8.

17. Kumar J, Fish $D$, Burger $H$, et al. Successful surgical intervention for the management of endocarditis due to multidrug resistant Candida parapsilosis: case report and literature review. Mycopathologia. 2011;172(4):287-92.

18. Mvondo CM, D'Auria F, Sordillo P, Pellegrino A, Adreoni M, Chiariello L. Candida parapsilosis endocarditis on a prosthetic aortic valve with unclear echocardiographic features. CVJA. 2013;24(3):e7-8.

19. Pepe DL, Anantha RV, Currie ME, McCormick JK, Mele T, Chu MW. Recalcitrant prosthetic valve endocarditis requiring repeated reconstruction: running out of options. Canadian J Cardiol . 2014;30(12):1732.e1735-1738.

20. Shokohi T, Nouraei SM, Afsarian MH, Najafi N, Mehdipour S. Fungal prosthetic valve endocarditis by Candida parapsilosis: a case report. Jundishapur J Microbiol. 2014;7(3):e9428.

21. Silva-Pinto A, Ferraz R, Casanova J, Sarmento A, Santos L. Candida parapsilosis prosthetic valve endocarditis. Med Mycol Case Rep. 2015;9:37-8.

22. Kabach M, Zaiem F, Valluri K, Alrifai A. Lower limb ischemia, Candida parapsilosis and prosthetic valve endocarditis. QJM. 2016;109(1):55-6.

23. Ahuja T, Fong K, Louie E. Combination antifungal therapy for treatment of Candida parapsilosis prosthetic valve endocarditis and utility of T2Candida Panel ${ }^{\circledR}:$ : A case series. IDCases. 2019;15:e00525.

24. Tan W, Dora A, Lluri G, Aboulhosn J. Candida parapsilosis endocarditis following transcatheter pulmonary valve implantation. World J Pediatr Congenit Heart Surg. 2020;11(1):112-3.

25. Neji S, Hadrich I, llahi A, et al. Molecular genotyping of Candida parapsilosis species complex. Mycopathologia. 2018;183(5):765-75.

26. Schubert $\mathrm{S}$, Kostrzewa M. MALDI-TOF MS in the microbiology laboratory: current trends. Curr Issues Mol Biol. 2017:23:17-20.

27. Croxatto A, Prod'hom G, Greub G. Applications of MALDI-TOF mass spectrometry in clinical diagnostic microbiology. FEMS Microbiol Rev. 2012;36(2):380-407.

28. Patel R. MALDI-TOF MS for the diagnosis of infectious diseases. Clin Chem. 2015;61(1):100-11.

29. Chopra T, Kaatz GW. Treatment strategies for infective endocarditis. Expert Opin Pharmacother. 2010;11(3):345-60.

30. Gould FK, Denning DW, Elliott TS, et al. Guidelines for the diagnosis and antibiotic treatment of endocarditis in adults: a report of the Working Party of the British Society for Antimicrobial Chemotherapy. J Antimicrob Chemother. 2012;67(2):269-89. 
31. Johnston BL, Schlech WF 3rd, Marrie TJ. An outbreak of Candida parapsilosis prosthetic valve endocarditis following cardiac surgery. J Hosp Infect. 1994;28(2):103-12.

32. Diekema DJ, Messer SA, Hollis RJ, Wenzel RP, Pfaller MA. An outbreak of Candida parapsilosis prosthetic valve endocarditis. Diagn Microbiol Infect Dis. 1997;29(3):147-53.

\section{Publisher's Note}

Springer Nature remains neutral with regard to jurisdictional claims in published maps and institutional affiliations.
Ready to submit your research? Choose BMC and benefit from:

- fast, convenient online submission

- thorough peer review by experienced researchers in your field

- rapid publication on acceptance

- support for research data, including large and complex data types

- gold Open Access which fosters wider collaboration and increased citations

- maximum visibility for your research: over 100M website views per year

At BMC, research is always in progress.

Learn more biomedcentral.com/submissions 